\title{
The Liverpool Lung Project: a molecular epidemiological study of early lung cancer detection
}

\author{
J.K. Field*,\#, J.H. Youngson*,\#
}

The Liverpool Lung Project: a molecular epidemiological study of early lung cancer detection. J.K. Field, J.H. Youngson. (C) ERS Journals Ltd 2002.

ABSTRACT: Lung cancer is the major cause of death from neoplastic disease in the world, and even with politically-motivated smoking cessation campaigns throughout Europe, the disease remains the major cause of death. The development of molecular epidemiological population-based research into early lung cancer detection, such as the Liverpool Lung Project (LLP), may provide a way forward. This is the first major molecular epidemiological study of detection of early lung cancer.

The use of molecular epidemiological risk assessments prior to clinical diagnosis and markers of preclinical carcinogenesis in patients with a high risk of developing lung cancer will reduce the incidence of clinically-detectable lung cancer, given the appropriate intervention strategies.

The aims are as follows: 1) to prepare a molecular genetic and epidemiological risk assessment model based on environmental exposures and genetic predisposition; 2) to develop an archive of specimens relating to at-risk individuals and those with lung cancer; 3) to redefine lung cancer based on molecular pathology using the fields of expression profiling, genetic instability and molecular cytogenetics; 4) to identify and assess novel markers of precarcinogenesis in high-risk populations; and 5) to facilitate the development of new treatment strategies (e.g. chemoprevention programmes and targeted drug therapies).

The LLP has two components: 1) a case-controlled study of newly-diagnosed cases of lung cancer that will provide a baseline, risk assessment; and 2) a prospective cohort study to be carried out over a 10-yr period that will identify markers of preclinical carcinogenesis. In-depth interviews are carried out using structured and semi-structured questionnaires. Sputum, blood and tumour specimens are collected and will be assessed for specific molecular markers (e.g. genetic instability, mutation and expression profiling, and methylation status).

Conclusions from The Liverpool Lung Project will be based around molecularepidemiological and genotyping risk assessment models, as well as redefining the disease, and ultimately contributing to the development of new early lung cancer detection and treatment strategies.

Eur Respir J 2002; 20: 464-479.
*Roy Castle International Centre for Lung Cancer Research, and ${ }^{\#}$ Dept of Clinical Dental Sciences,

The University of Liverpool, Liverpool,

UK.

Correspondence: J.K. Field

Roy Castle International Centre for Lung Cancer Research

200 London Road

Liverpool

L3 9TA

UK

Fax: 441517948989

E-mail: J.K.Field@liv.ac.uk

Keywords: Cancer

early detection

epidemiology

lung

molecular

protocol

Received: October 292001

Accepted after revision: April 182002

This research project was funded by the Roy Castle Lung Cancer Foundation, Liverpool, UK.
Lung cancer is the major cause of death from neoplastic disease in the world. Europe is presently beset by a lung cancer epidemic, and even with politically motivated smoking cessation campaigns, the disease remains the major cause of death. Unfortunately, it is now clear that new smoking cohorts are emerging in children in their early teens. When this information is considered, alongside the fact that the majority of individuals who develop lung cancer in the
USA are former smokers, this creates a major social problem.

There are $>38,000$ new cases of lung cancer per year in the UK, and this incidence is amongst the highest in Europe. Although the incidence is declining in some male populations, it is rising steadily in women $[1,2]$. Merseyside has some of the highest incidence rates in the UK, with little evident decline in males and a $30 \%$ increase in females aged $<75$ yrs between 1992-1995

\footnotetext{
Previous articles in this series: No. 1: Steels E, Paesmans M, Berghmans T, et al. Role of p53 as a prognostic factor for survival in lung cancer: a systematic review of the literature with a meta-analysis. Eur Respir J 2001; 18: 705-719. No. 2: van Klaveren RJ, Habbema JDF, Pedersen JH, de Koning HJ, Oudkerk M, Hoogsteden HC. Lung cancer screening by low-dose spiral computed tomography. Eur Respir J 2001; 18: 857-866. No. 3: Brambilla E, Travis WD, Colby TV, Corrin B, Shimosato Y. The new World Health Organization classification of lung tumours. Eur Respir J 2001; 18: 1059-1068. No. 4 : Brock CS, Lee SM. Anti-angiogenic strategies and vascular targeting in the treatment of lung cancer. Eur Respir J 2002; 19: 557-570. No. 5: Hirsch FR, Merrick DT, Franklin WA. Role of biomarkers for early detection of lung cancer and chemoprevention. Eur Respir J 2002; 19: 1151-1158.
} 
[3]. In the Liverpool area, the cumulative rate (0-74 yrs) in 1994-1995 was $11.6 \%$ for males and $7.2 \%$ for females, compared with a national average of $7.2 \%$ for males and $3.1 \%$ for females in 1995 [3, 4]. Detection of lung cancer usually occurs late in the disease, when it is beyond effective treatment; consequently, there is a high mortality rate and a 5-yr overall survival rate of $6 \%$ in Merseyside [5].

The development of a molecular epidemiological population-based study of early lung cancer detection could provide answers to some of the major questions posed in lung cancer. It is for this reason that the current authors have set up the Liverpool Lung Project (LLP). Conclusions from the LLP will be based around molecular-epidemiological and genotyping risk assessment models, redefining the disease, and ultimately contributing to the development of new treatment strategies (e.g. chemoprevention and targeted drugs).

This is the first major molecular epidemiological study of the detection of early lung cancer; however, substantial pieces of work have been published on the epidemiology of lung cancer [6] in the fields of smoking associations [7], occupational exposures [8,9], diet [10] and social status [11]. Recently, there has been a dramatic increase in the number of publications in the field of genotype studies and deoxyribonucleic acid (DNA) repair [12, 13] associations with lung cancer. The future lies in combining the data from such analyses [14], in order to develop robust risk assessment models that can contribute to future chemopreventive programmes [15]. The LLP's objective is to achieve these aims. Currently, the present authors have enrolled $>3,000$ individuals at a cost of $\sim £ 1$ million $\cdot \mathrm{yr}^{-1}$. This study has been planned over a 10 -yr period in order to recruit 500 cases of lung cancer for the cohort study, which will provide adequate statistical power.

\section{Risk factors for lung cancer}

\section{Smoking and lung cancer}

Use of tobacco products and, in particular, cigarette smoking, are responsible for the majority of lung cancer cases, with an estimated attributable risk of $\sim 90 \%$ in males and $80 \%$ in females $[16,17]$. Such attributable proportions are place specific and depend on the prevalence of tobacco smoking and of other exposures. It is important to realise that the sum of the proportions of a disease attributable to different risk factors may exceed $100 \%$ because of the multiple pathways in the carcinogenic process. The fact that $90 \%$ of lung cancers are due to tobacco does not mean that only $10 \%$ are attributable to all other causes. The concept of interactions in the contribution to risk is exemplified by the importance of gene-environment interactions and the carcinogenic potency of complex mixtures. The incidence rates in nonsmokers in the USA have been reported as 14.7 per 100,000 in males and 12.0 per 100,000 in females [18], also indicating that other risk factors may be important. The smoking-associated risks are dependent on the age of starting to smoke, the duration of smoking, and the level and pattern of smoking.

It is clear that the risk of lung cancer may be substantially reduced, dependent on the duration of smoking and age at cessation. It is also becoming apparent that many exsmokers remain at high risk because of genetic damage present in the bronchoalveolar epithelial cells. Smoking during adolescence may lead to accumulated DNA damage demonstrable many years later [19].

Smoking levels in adults declined to $28 \%$ in 1996 , but this decline is concentrated in the higher socioeconomic groups (SEG) and age-specific groups. Rates have declined very little in people aged $<24$ yrs since the 1970 s, with no decrease over this time in females aged $<19$ yrs. Smoking prevalence in 1998 was highest at $42 \%$ amongst those aged 20-24 yrs [20], and $26 \%$ of $15 \mathrm{yr}$ olds were regular smokers, while $63 \%$ have tried smoking. Smoking is a major confounder in the assessment of other risk factors, and accurate estimates of smoking levels are required for adjustment in multivariate analysis.

The role of passive smoking has also been examined with relation to an increase in lung cancer risk in nonsmoking adults living with smokers. A recent meta-analysis [21] found an excess risk of $24 \%$ among lifelong nonsmokers with partners who smoked (relative risk 1.24, 95\% confidence interval 1.13-1.36). Furthermore, a significant dose-response relationship was identified.

\section{Occupational exposure and lung cancer}

Lung cancer is ranked second only to bladder cancer in the proportion of cases thought to be due to occupational exposures [22], with an estimated attributable risk in the region of $15 \%$ [23]. Associations between certain exposures and a significantly increased risk of developing lung cancer have been reported in many studies. Twenty-two chemicals, groups of chemicals or mixtures that are used in industrial or agricultural settings have been classified as established human carcinogens in the International Agency for Research on Cancer (IARC) monograph series, of which 14 are believed to act upon lung tissue [24]. A further 22 chemicals have been classified as probably carcinogenic and 91 as possibly carcinogenic [25]. Many of the current estimates of attributable risk for occupational exposures in lung cancer are wide $(4-40 \%)[23,26]$ and would be expected to vary in time and place. The synergistic effect of cigarette smoking and exposure to specific chemicals may, in part, account for high rates of lung cancer among workers in particular industries.

\section{Air pollution and lung cancer}

The dramatic increase in morbidity and mortality that occurred as a result of high air pollution levels in London in the 1950s directed attention on the relationship between air pollution and health. Apart from the obvious human cost of morbidity and mortality, a 
report by the British Lung Foundation [27] has placed the approximate health costs arising from road transport air pollution at $>£ 11$ billion per annum. Over 40 compounds considered to be carcinogenic or probably carcinogenic are found in air pollution. The presence of these compounds among air pollutants supports the hypothesis that air pollution may increase the risk of lung cancer [28].

A major drawback of previous studies has been the inadequate characterisation of air pollution exposure [29]. Very few studies have been conducted that provide detailed information on personal exposures, interperson variability in exposure and a correlation of these exposures with levels measured at fixed-site monitors. Air pollution comprises a large number of compounds that are usually correlated over relatively short time periods, but changes in emissions over long time periods may result in substantial modification.

\section{Diet and lung cancer}

Dietary factors may be important in the aetiology of lung cancer; however, research on the association between diet and lung cancer remains inconclusive. Smoking levels and diet correlate with social deprivation, and smokers tend to consume diets lower in antioxidants and with fewer vegetables and fruits [30-32]. The evidence on fat and cholesterol from both case-controlled and cohort studies is mixed. Some studies suggested increased risk with higher fat or cholesterol intake [33-38], while others found no association [39-41]. The role of a high-fat diet in relation to increased risk of lung cancer is biologically plausible [42]. Alcohol consumption is strongly associated with smoking, and a significant increase in lung cancer risk with high alcohol intake, adjusted for cigarette smoking, has been shown [43-47]. Alcohol may act as a solvent for carcinogens, especially those in cigarette smoke [48], but residual confounding with tobacco may exist and explain much of the observed association.

There have been many studies of fruit and vegetable intake and most are consistent with a protective effect [38, 44, 49-52]. Some found a statistically significant decrease in risk with higher carotenoid intake.

Many studies have also found a protective effect for vitamin $\mathrm{C}$, although in many cases the association is weak [33, 44, 53-58]. It is possible, however, that the decrease in risk is actually due to some other compound in foods containing these substances, or an aspect of lifestyle related to consumption of such foods. Selenium plays an important part in the metabolism of glutathione peroxidase, an enzyme that protects against oxidative change. Three large studies have examined the role of selenium and found a protective effect [59-62], but a recent review of epidemiological studies on diet and lung cancer over the last 20 yrs [63] concludes that they have not provided overwhelming evidence that diets low in fats and high in fruit, vegetables and antioxidants are associated with reduced lung cancer risk.

\section{Social class and lung cancer}

Inequalities in health are one critical facet of social inequality [64]. Health inequalities are manifested in numerous ways (e.g. lack of access to healthcare, lack of health education, a concomitant lack of understanding of the significance of symptoms, differential referral patterns to cancer specialists). These could explain why lower SEG is associated with poorer survival from lung cancer. As lung cancer is a disease affecting many older people, an additional group who may be socially disadvantaged is the elderly, having lower levels of diagnostic investigation and treatment than their younger counterparts. A previous local study [65] demonstrated variations in treatment by age and district of residence.

It is an undeniable fact that there is an inverse relationship between social class and lung cancer [66-68]. Essentially, the risk of developing lung cancer is significantly higher in the more disadvantaged sections of society. A recent study, examining the relationship between social deprivation and cancer in Scotland [69], observed a three-fold difference for lung cancer between the most and least deprived areas. Factors that could, in part, explain the association between lung cancer and lower SEG include smoking, diet, occupational exposures, and exposure to environmental pollution with area of residence. Results from a recent cohort study suggest an additional risk due to poor lung health, deprivation and poor socioeconomic conditions throughout life [70].

\section{Family history and lung cancer}

Family studies have shown a two- to three-fold increase in risk in nonsmokers who have relatives with lung cancer compared to nonsmokers with no family history $[71,72]$. Many studies suggest that there may be inherited tumour suppressor genes or oncogenes relating to the development of lung cancer, or a genetically-determined ability to metabolise carcinogens. One study suggested that virtually all lung cancer occurs among gene carriers [73], but the current evidence is conflicting and many studies lack the power to detect small risks due to factors other than smoking. While a shared environment may also explain the familial aggregation, some genetic markers for susceptibility have been suggested. These include polymorphisms of CYP1A1, which is responsible for the metabolic activation of benzopyrene, CYP2D6 and glutathione S-transferase (GST) that catalyse the conjugation of polycyclic aromatic hydrocarbons (PAH).

\section{Genetic susceptibility and lung cancer}

Humans are constantly exposed to chemical carcinogens in their everyday lives, but only a small proportion of those with the highest exposure (i.e. smokers) develop lung cancer. Since many carcinogenic compounds require metabolic activation to 
enable them to react with cellular macromolecules, individual features of carcinogen metabolism may play an essential role in the development of environmental cancer.

Epidemiological evidence suggests that the genes controlling the metabolism of carcinogens and antioxidant or nutritional status are associated with lung cancer risk, possibly through their ability to modulate DNA damage by carcinogens. Since many carcinogenic compounds require metabolic activation to enable them to react with cellular macromolecules, individual features of carcinogen metabolism may play an essential role in the development of environmental cancer [74].

Cytochrome P450s are a superfamily of oxidising enzymes, the majority of which are involved in the metabolism of xenobiotics [75]. Most xenobiotics found in tobacco smoke require metabolic activation before they exert carcinogenic activity. For instance, transformation to the ultimate carcinogen of Benzo- $\alpha-$ pyrene (BP) can occur by co-oxidation in the presence of various fatty acids. It is conceivable that BP from tobacco smoke is readily oxidised to the ultimate carcinogen as a consequence of a high fat diet [42]. CYP1A1, one of the most extensively studied P450s, is not expressed above a basal level in any human tissue except the lungs of smokers [1], but has been shown to be highly inducible by PAH [77]. The combined effect of vitamin status and genetic susceptibility on DNA damage may explain why individuals exposed to PAH have greater lung cancer risk than others with comparable exposures [78].

Aromatic amines (aryl- and heterocyclic) are a class of carcinogens present in both diet and cigarette smoke [79]. They can be $N$ - or $O$-acetylated by the polymorphic arylamine $\mathrm{N}$-acetyltransferase (NAT) 1 or NAT2 enzymes, resulting in activation or, in some cases, detoxification. NAT2 is considered to be a susceptibility factor for a number of malignancies. Carriers of the NAT $2 * 4 / * 4$ genotype, with its especially high acetylation capacity, are at significantly increased risk of lung cancer [80].

The relative risk of individuals with a combination of both a homozygous rare allele of CYP1A1 and a null GST1 was "remarkably high" at 5.8 for lung cancer and 9.1 for squamous cell carcinoma, compared with other combinations of genotypes [81]. The role of genetic susceptibility remains somewhat controversial. BRAUN et al. [82] concluded that genetic factors could not be used to predict lung cancer risk in male smokers $>50$ yrs. This came from their analysis of 15,924 pairs of mono- and dizygotic twins. There was no greater concordance in lung cancer death between monozygotic twins than with dizygotic twins, even when smoking histories were similar. However, there is a considerable body of evidence to the contrary.

The limitation of most of the studies undertaken to date has been a low number of cases included. In a recent review of 17 studies, an average of only 137 cases (range 35-447) were analysed for GSTM1 polymorphisms [83]. Heterogeneity of these studies is the main reason for uncertain results and even metaanalysis has failed to show a precise estimate of the true odds ratio. The failings in study design and lack of statistical power in many studies have been recently well described by D'ERRICO et al. [84].

\section{Early detection biomarkers}

\section{Deoxyribonucleic acid methylation analysis}

Aberrant DNA methylation within $\mathrm{CpG}$ islands is common in human malignancies leading to abrogation or overexpression of a broad spectrum of genes [85]. Abnormal methylation has also been shown to occur in $\mathrm{CpG}$-rich regulatory elements in intronic and coding parts of genes for certain tumours [86]. Using restriction landmark genomic scanning, CosTello et al. [87] were able to show that methylation patterns are tumour-type specific. Highly characteristic DNA methylation patterns could also be shown for breast cancer cell lines [88]. Genome-wide assessment of methylation status represents a molecular fingerprint of cancer tissues, as does large scale messenger ribonucleic acid (RNA) expression monitoring, and therefore should allow tumour class prediction and discovery.

Recently, an application of methylation specific polymerase chain reaction (MSP) in serum of patients with nonsmall-cell lung cancer has been published [89]. The assumption is that tumour cells may release DNA into the circulation, which is enriched in serum and plasma. After purification, $1 \mathrm{~mL}$ of serum yields $\sim 50 \mathrm{ng}$ of DNA. In a series of 22 patients, four genes were examined for the presence of methylated $\mathrm{CpG}$ islands. In $68 \%$ (15 out of 22 ) of the tumours, aberrant methylation in at least one of the genes was present, but not in the normal tissue. In 11 out of $15(50 \%$ of total), abnormal methylated DNA was demonstrated in the matched serum samples. In another study of the same group, bronchoalveolar lavage (BAL) samples were examined. In 12 cases methylation of one gene (p16) was found in BAL fluid (19 tumours with methylation out of a total of 50). The other 38 were negative with MSP [90]. Recently, the feasibility of using methylation studies to detect early cancer has been demonstrated, with MSP in sputum with a sensitivity of 1/50,000 alleles [91] and detection of P16 and $\mathrm{O}^{6-}$ methylguanine-DNA methyltransferase promoter methylation 1-3 yrs before cancer diagnosis. It is of note that p16INK4 promoter hypermethylation and p53 mutations have been found at a high frequency in exfoliative material (i.e. sputum, BAL, brushings) from symptomatic chronic smokers and mark the development of lung cancer $[92,93]$. These findings emphasise the possible relevance of methylation detection of early lung cancer.

\section{Genomic instability}

Genomic instability is the most common molecular abnormality in human tumour cells [94, 95]. One form of genomic instability is allelic imbalance or loss of heterozygosity (LOH), which reflects epigenetic changes such as aneuploidy, polyploidy, losses and 
amplifications of chromosomal regions. The other form of genomic instability is microsatellite instability (MIN) or (MSI); also referred to as microsatellite alterations (MA) or replication errors (RER), representing replication and DNA repair infidelity. The high incidence of genomic instability in lung tumours has been well established [96-100] and in some cases it has been associated with prognosis [101-103]. The present authors have recently demonstrated genetic alterations in $97.6 \%$ of lung tumours examined by a panel of 12 microsatellite markers selected at specific locations [104], and have calculated the threshold of $\mathrm{LOH}$ detection to $23 \%$ by assessing the interassay variation.

Lung cancer is the most common cause of neoplasia-related death worldwide. Moreover, it usually has a very poor prognosis with a $\leqslant 6 \% 5$-yr survival. One of the reasons for this low survival is that cancer is most often diagnosed when it is beyond effective treatment. Thus, there is an increasing demand for new early lung cancer detection tools $[105,106]$. Lung cancer develops through a multistage process of steps with increasing genomic instability. Genetic alterations have been detected in preneoplastic lung [107-109] lesions as well as in bronchial tissue from smokers with no evidence of lung malignancy $[110,111]$. DNA aberrations precede morphological transformation [112] and, thus, are favourable markers and potential tools for the identification of individuals at high risk for developing lung cancer. It has been previously shown that genomic instability can be detected in bronchial lavage (BL) and sputum and this may be one of the ways forward to assist in early diagnosis of lung cancer [113-116]. The present authors have demonstrated genomic instability in the BL from a number of individuals with no clinical evidence of lung cancer, posing a question about exclusive occurrence of genomic instability in cancer. This observation was also supported by reports of genomic instability in nonmalignant diseases [117-123].

The technological advantages of fluorescence polymerase chain reaction (PCR)-based assays provide the ability to detect DNA changes from minute amounts of starting material in multiplex reactions [124]. Furthermore, automated analysis on sequencers/ genetic analysers not only increases throughput but also reduces operator errors during analysis. The present authors have already examined the incidence of genetic alterations in 65 microsatellite markers in lung cancer specimens and have shown that allelic imbalance in some chromosomal regions appears to be cancer specific while others are not [125]. The aim of this aspect of the study is thus to identify cancerspecific microsatellite marker assay(s) to be applied to $\mathrm{BL}$, sputum and plasma/serum specimens in order to assist in the early diagnosis of the disease. Ninety-six lung tumour specimens with 65 microsatellite markers have already been screened, and the 24 most informative to assay for cancer specificity have been chosen by examining $100 \mathrm{BL}$ specimens from lung cancer patients and 100 specimens from individuals with nonmalignant lung diseases.
Genome-wide lung cancer expression analysis: identifcation and investigation of genes linked to the lung cancer phenotype

Chronic exposure of the bronchial epithelium to carcinogenic agents (such as those present in tobacco smoke) appears to lead to focal epithelial changes (hyperplasia, dysplasia, carcinoma in situ) that are scattered throughout the tracheobronchial tree $[126,127]$. These overt cellular changes may be preceded by the widespread proliferation of apparently histologically normal but genetically damaged clones of cells, presumably as the result of an acquired growth advantage. This growth advantage will be conferred by gene mutation and gene misregulation. In frequent smokers, lung tumours are therefore likely to arise from, and against, a background of multiclonal, genetically altered, premalignant cells.

The present authors and others have shown that both genetic damage and inappropriate gene expression may be useful predictors of both early or preneoplasia and of the clinical behaviour of lung tumours [113, 128-131].

One of the most promising approaches to the early detection of lung cancer is based on the observation that premalignant cells are shed from developing lesions, most likely as a consequence of the level of structural disorder of the tissue, and that these cells may be detected in the sputum of individuals perhaps several years before overt disease can be recognised by conventional procedures $[128,132]$. In order to use such a technology most effectively, a complete picture of the nature of gene expression in tumour cells is required, such that a panel of highly specific antibody diagnostics (or reverse transcriptase PCR (RT-PCR) assays) against key targets may be developed and tested. The LLP-generated sputum and blood samples will constitute an extremely valuable experimental resource for the validation of novel diagnostic reagents.

The aim is therefore to carry out a genome-wide expression analysis of human lung cancer: to redefine the disease at the molecular level. The power of such an approach has recently been highlighted in a study of B-cell lymphoma [133].

\section{Cytological analysis of lung tumours}

Cytological changes in clinical samples have long formed the basis of cancer diagnosis. The simplest method of screening for cancerous changes in the airways is to analyse exfoliated cells in sputum samples $[112,134]$. Alternatively, when patients present for evaluation of a possible lung tumour, a sample of cells is collected by BL [113].

However, several studies have indicated that multiple genetic changes are already present in the apparently normal bronchial epithelium of smokers $[110,111]$. A number of biomarkers have been evaluated for early diagnosis of lung cancer but none have yet been found robust and reliable enough for routine screening [135]. It is clear that much more needs to be known about the development of lung 
cancer before suitable markers can be used for screening. Cell-based studies have the benefit of allowing the analysis of very small samples with high sensitivity and specificity. These studies can be based on DNA changes, or on the downstream effects of genetic change resulting in alterations to cellular proteins, since both DNA and protein remain relatively stable in clinical samples.

\section{Molecular cytogenetic analysis of lung tumours}

Molecular cytogenetic analysis of cytological specimens has the potential to detect changes in single cells and thus is likely to be more sensitive than PCR-based methods of screening. Chromosome copy changes have been reported in the normal bronchial epithelium of lung cancer patients [136-138], but most fluorescence in situ hybridisation (FISH) studies have used centromeric probes, which give good signals but may not be sufficiently informative for tumour-specific changes [139-141]. A more specific set of probes is required to provide better discrimination between general epithelial disturbance and actual tumour development. This means that there should be a thorough analysis of chromosomal changes in lung tumours.

Identification of tumour-specific chromosome changes in lung cancer. Lung tumours frequently show extensive chromosome changes, with gains and losses of many chromosome segments, often generating marker chromosomes whose origin is not immediately apparent [142-144]. Molecular cytogenetics, using FISH techniques, allows us to examine the content of marker chromosomes in great detail. However, the complexity of chromosome changes seen in lung tumours makes it difficult to determine what changes, if any, are important in the development of the disease. An answer will only emerge after the thorough analysis of many tumours.

Analysis of chromosome changes in lung cancer by comparative genomic hybridisation. Conventional cytogenetic analysis is done on metaphase chromosomes, which means that the cells must be cultured in the laboratory to obtain sufficient dividing cells for analysis. Unfortunately, the success rate for culturing lung tumours is known to be low $(<30 \%)$ and squamous cell carcinomas are particularly difficult in this respect [142]. Consequently, comparative genomic hybridisation $(\mathrm{CGH})$ is a particularly valuable method for analysing the gain or loss of chromosome segments in these types of tumours [145]. A number of CGH studies have been performed on lung tumours and a body of data is accumulating [146, 147], however the technique is complex and inadequate quality control can affect the reliability of results. It is also possible that variations in carcinogen exposure and genetic background in different populations may result in differences in chromosomal changes. Therefore, it is important to establish the pattern of chromosomal changes in lung tumours in individuals from the Merseyside region in relation to other populations.

\section{Evaluation of protein markers in lung tumours}

The downstream effects of genetic changes in cells can also be analysed by comparing the distribution of RNA or proteins in normal and tumour cells. These patterns can be examined across a range of cell types within tissue sections or tissue arrays, using in situ hybridisation or immunohistochemistry. Changes in the normal pattern of staining can then be correlated with disease stage, and potential candidates evaluated for clinical significance.

\section{Risk assessment research}

The way forward for improved management and prognosis for the common cancers lies with early detection of disease. Economics will dictate that screening for lung cancer will not be available for the entire population. Therefore, there is a major need to be able to identify those people at highest risk of disease who would benefit from prevention measures. The causes of common cancers may have their basis in environmental exposures occurring in the genetically predisposed host. It is essential, therefore, that the interaction between lifestyle factors and susceptibility genes can be studied to produce a risk assessment model. The major strength of the LLP lies in the potential to carry out this work.

\section{Objectives of the Liverpool Lung Project}

The use of molecular-epidemiological risk assessments prior to clinical diagnosis and markers of preclinical carcinogenesis in patients with a high risk of developing lung cancer will reduce the incidence of clinically detectable lung cancer, given the appropriate intervention strategies.

\section{Aims}

To prepare a molecular genetic and epidemiological risk assessment model based on the analysis of environmental exposures and genetic predisposition, which will provide an algorithm to measure an individual's risk for developing lung cancer.

There are five major aims of the LLP: 1) to prepare a molecular genetic and epidemiological risk assessment model based on the analysis of environmental exposures and genetic predisposition, which will provide an algorithm to measure an individual's risk for developing lung cancer; 2) to develop an archive of specimens relating to at-risk individuals and those with lung cancer; 3 ) to redefine lung cancer based on molecular pathology using the fields of expression profiling, genetic instability and molecular cytogenetics; 4) to identify and assess novel markers of precarcinogenesis in the high-risk populations; and 5) to facilitate the development of new treatment strategies, i.e. chemoprevention programmes and targeted drug therapies. 


\section{Study design}

If the results are to be widely applicable it is important that the study is population based. Therefore, the LLP is being conducted in a defined geographical area of Merseyside, based on contiguous electoral wards with a high incidence of lung cancer. The LLP has two components. Firstly, a casecontrolled study of newly diagnosed cases of lung cancer, which will provide a baseline risk assessment. Secondly, a prospective cohort study which provides serial samples to identify markers of preclinical carcinogenesis and contemporaneous lifestyle data (fig. 1).

Case-controlled study. Twelve hundred and fifty newly diagnosed cases of lung cancer will be entered into the study. Two controls per case, matched for age and sex, will be randomly selected from the study area population. All cases of epithelial tumours of the trachea, bronchus and lung will be included. Approaching newly diagnosed lung cancer cases to invite them to take part in a research project is difficult. Cases are initially identified from many sources including pathology reports, specialist lung cancer nurses, the palliative care team, and clinicians in the lung cancer rapid access and oncology clinics. This work is carried out by a research nurse, working with the clinical teams.
Cohort study. All residents, aged 45-79, within the study area (total of 326,000 ) will be eligible for entry into the study. A random selection of 7,500 people will be chosen from this population via the general practitioner's (GP's) lists. All the GPs who have practices within the study area have been asked to collaborate with the project and an $\sim 2 \%$ sample of each $\mathrm{GP}^{\prime} \mathrm{s}$ patients will be included. An anonymous list of patients registered with collaborating GPs is held in the study centre. Randomised samples are drawn from each GP list, with individuals identified by a study number. Invitation letters for cohort and control subjects are sent out from Central Operations Group office.

Exclusions. All exclusions are monitored, analysed for bias and recorded. Primary reasons for exclusion include: subject refusal, inability to contact the subject, subject resident outside the study area, refusal to approach by a clinician and the subject too ill or unsuitable for interview. The subject may be considered unsuitable if, for example, they have advanced senile dementia or are otherwise unable to understand the project sufficiently to give informed consent.

\section{Power calculations}

Cohort study. In a cohort of 7,500 persons, followedup over $10 \mathrm{yrs}$, the present authors expect to see 500 cases, assuming an incidence rate of approximately

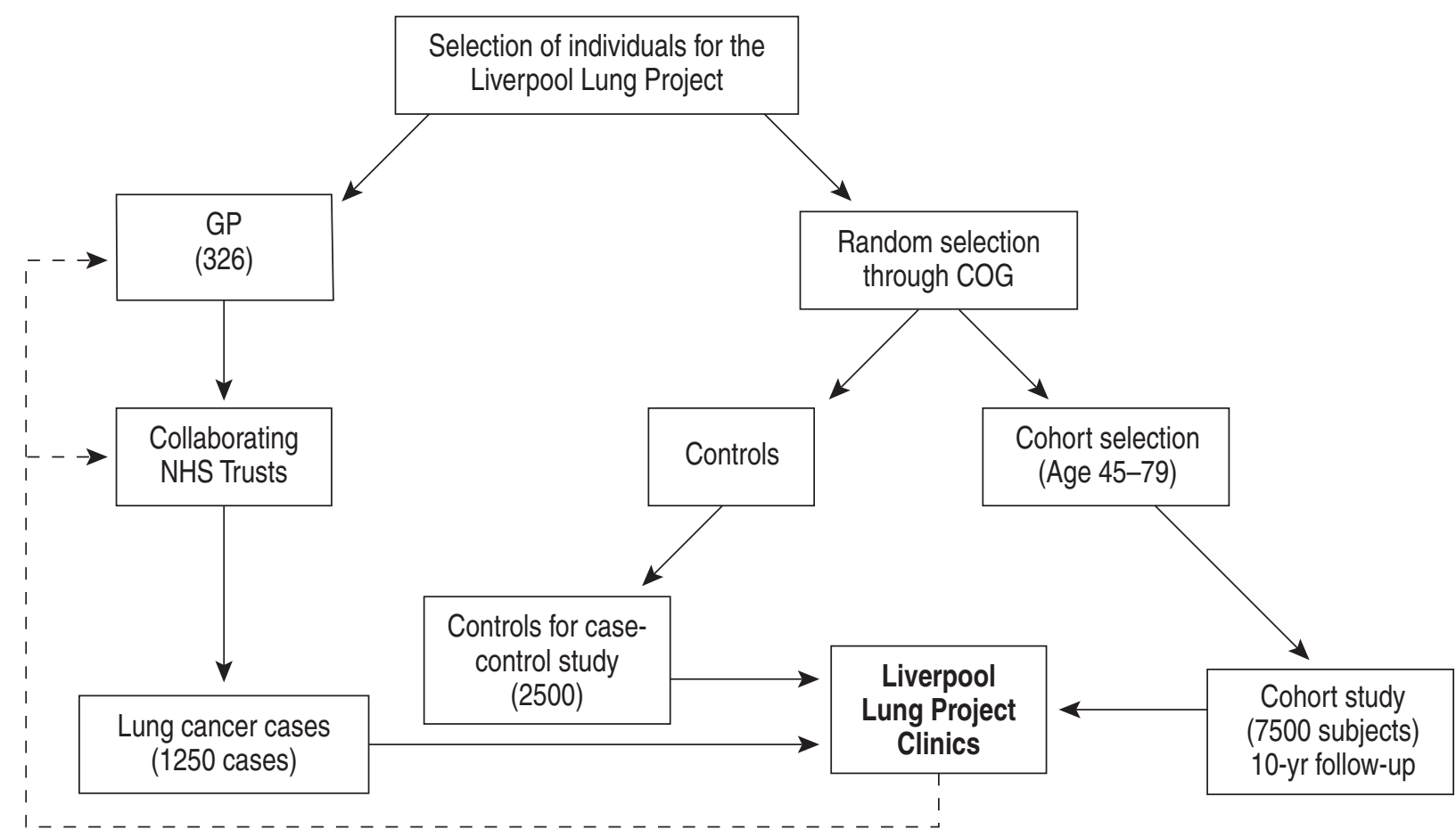

Fig. 1.-Selection of individuals for the Liverpool Lung Project. This flow diagram illustrates the mechanism by which individuals are recruited into case-controlled and cohort studies. Case-controlled study: 1,250 newly diagnosed cases of lung cancer will be entered into the study. Two controls per case, matched for age and sex, will be randomly selected from the study area population. Cohort study: all residents, aged 45-79 yrs, within the study area (total of 326,000) will be eligible for entry into the study. A random selection of 7,500 people will be chosen from this population via general practitioner (GP) lists. All the GPs who have practices within the study area have been, or will be, asked to collaborate with the project and an $\sim 2 \%$ sample of each of the GP's patients will be included. COG: Central Operations Group at the Health Authority in Liverpool. The dotted line illustrates the information flow regarding clinical findings from the Liverpool Lung Project clinics back to the relevant health care professions and National Health Service (NHS) Trusts. 
eight in 1000 . This will give power of $>95 \%$ to detect risk ratios of 2.0 at the $5 \%$ significance level. The pilot study has demonstrated that 1,000 people can be recruited into the cohort, provide samples and complete the questionnaires, in a single research clinic in $1 \mathrm{yr}$.

Case-controlled study. Approximately 1,000 new cases of lung cancer are diagnosed in the LLP study area every year, around 350 in females and 650 in males $<80$ yrs. For exposures with a control prevalence of $5 \%$, the proposed study would be able to detect relative risks of 1.75 at the $5 \%$ significance level with a power of $95 \%$, or relative risks of 1.5 with a power of $80 \%$, given a recruitment of 1,250 cases.

\section{Analysis}

Multivariate conditional logistic regression will be used for both the case-controlled and cohort studies, the latter being analysed primarily as a nested study. The risk assessment model will be based on data from the case-controlled study. This will later be validated and possibly refined by data from the cohort study. Variable selection will be critical and several different approaches will be taken and compared, black-box stepwise selection will not be used alone. Furthering work embodied in MiLler [148], this is an ongoing area of statistical research. Given the nature of the data collection, the present authors also propose to incorporate and extend the methods of CARROLL et al. [149] to allow for measurement error.

Some simpler nonglobal, and even univariate analyses, will also be presented for ease of interpretation and comparison. There will be some survival analysis regarding time to onset of disease following occurrence of precursor markers, based on the cohort study. Subanalyses will be made by tumour cell type, and the present authors will build risk assessment models for environmental, occupational, lifestyle, dietary, and genetic risks in isolation and in subsets. This will enable the present authors: 1) to study their contributions to the total attributable risk, and 2) to validate the findings against those of other studies where global models have not been possible. Due to the dangers of multiple hypothesis testing all subgroup analyses will be presented with suitably strong caveats. There will be no interim analysis of either the case-controlled study or the cohort study.

\section{Ethical issues and informed consent}

Ethical approval for the LLP was initially obtained from the three Local Research Ethics Committees between October 1997 and February 1998.

Further ethical approval was obtained in March 2000 for the more detailed information sheets and consent form for DNA and tissues samples which had been drawn up to comply with the draft new Medical Research Council guidelines [150].

\section{Epidemiological data}

The methodology, with regard to the structured interview and obtaining specimens, is essentially the same for the two elements of the LLP. An in-depth interview will be carried out using structured and semi-structured questionnaires. Those subjects who return for follow-up will complete a short form of the questionnaires aimed at recording any changes in lifestyle over the interval since their last attendance.

The lifestyle questionnaire has been developed in-house and covers areas such as active and passive smoking history, residential history, medical history, family history and hormonal history (for females). The residential history will be correlated with environmental pollution monitoring data. This work includes the production of detailed maps for each pollutant, from current and historical data.

The methodology for assessing occupational exposure has been developed by SiEMIATYKI et al. [151] in Canada. These methods are based on expert judgement applied to job descriptions obtained through detailed and structured interviews.

\section{Occupational exposure assessment}

One of the most complicated aspects of populationbased studies of occupational cancer risk is retrospective exposure assessment. New methods have been developed in order to avoid the errors involved in using job titles as surrogates for exposures, or selfreporting of exposures. These methods are based on expert judgement applied to job descriptions obtained through detailed and structured interviews [151-154].

This methodology has been adopted for the multicentre case-controlled study of Occupation, Environment and Lung Cancer in Countries of Central and Eastern Europe co-ordinated by IARC.

\section{Dietary assessment}

The role of dietary factors will be assessed using a food frequency questionnaire, closely based on that used for the multicentre European Prospective Investigation of Cancer study of diet and cancer, modified for local diets. The questionnaire will be validated with a 5-day food diary.

\section{Estimation of exposure to environmental pollution}

The assessment of an individual's long-term exposure to air pollutants is not a simple task. The available data from monitoring programmes must be extrapolated, or at least interpolated, both in time and space. However, the density of the monitoring networks is not sufficient to map air pollutant concentrations by simple numerical interpolation since the temporal and spatial variability of air pollutant concentrations is too large. Scientists at the National Environmental Technology Centre, AEA Technology, have developed alternative mapping methods for air 
pollutant concentrations based on the relationships found between pollution measurements and variables such as population density, land use or road traffic density for which detailed spatial data are available. These methods allow the production of air pollutant maps at $1 \mathrm{~km}^{2}$ resolution. Currently, maps are available for 1994 and 1996 for nitrogen dioxide, sulphur dioxide, carbon monoxide, benzene and particles with an $50 \%$ cut-off aerodynamic diameter of $10 \mu \mathrm{m}$.

\section{Conclusion}

Consideration must be given to the redefinition of lung cancer using molecular biology approaches because the classic pathological and clinical methods are inaccurate. The present authors are planning to undertake genome wide expression profiles, so are in a particularly strong position to undertake this task. The importance placed internationally on spiral computed tomography (CT) early lung cancer detection trials has been taken into account, spiral CT will play an important role in the public image and clinical approach to early lung cancer detection. Thus, the present authors are in a particularly strong position to propose future research programmes that may be run in collaboration with such trials, i.e. spiral CT early lung cancer trials.

The results of the LLP research programme will make a significant contribution to the risk assessment of individuals who may develop lung cancer, as well as providing methods of identifying genetic aberrations in bronchial cells prior to a clinical diagnosis of the disease. The present authors are now in a position to make a major contribution to the clinical and scientific community in the ability to undertake a redefinition of lung cancer based on expression profiling, which will lead to the provision of specific early detection markers as well a providing targets for future therapy.

The flow diagram of the LLP (fig. 2) indicates the contribution this research programme can make to the identification of individuals who are at risk of developing lung cancer, as well as the molecular/ pathological definition of the disease with the contribution of these research modalities into future intervention and treatment modalities.

This is a unique project and its major strength lies in the combination of epidemiology and molecular genetics and its successful completion should have a major impact on the prevention and management of lung cancer.

\section{Appendix}

\section{Liverpool Lung Project management}

The cohort study design is based on randomised selection of a population sample invited to take part by letter. Subjects who agree to take part are then given an appointment for a nurse-led research clinic. This enables full informed consent to be obtained, a full medical history to be obtained and a basic health check to be carried out. Blood and sputum samples can be collected in a safe environment, according to the study protocols, and the subject can then spend time with one of the medical interviewers to complete the questionnaires.

The project manager is responsible for the day to day running of the project. The project management

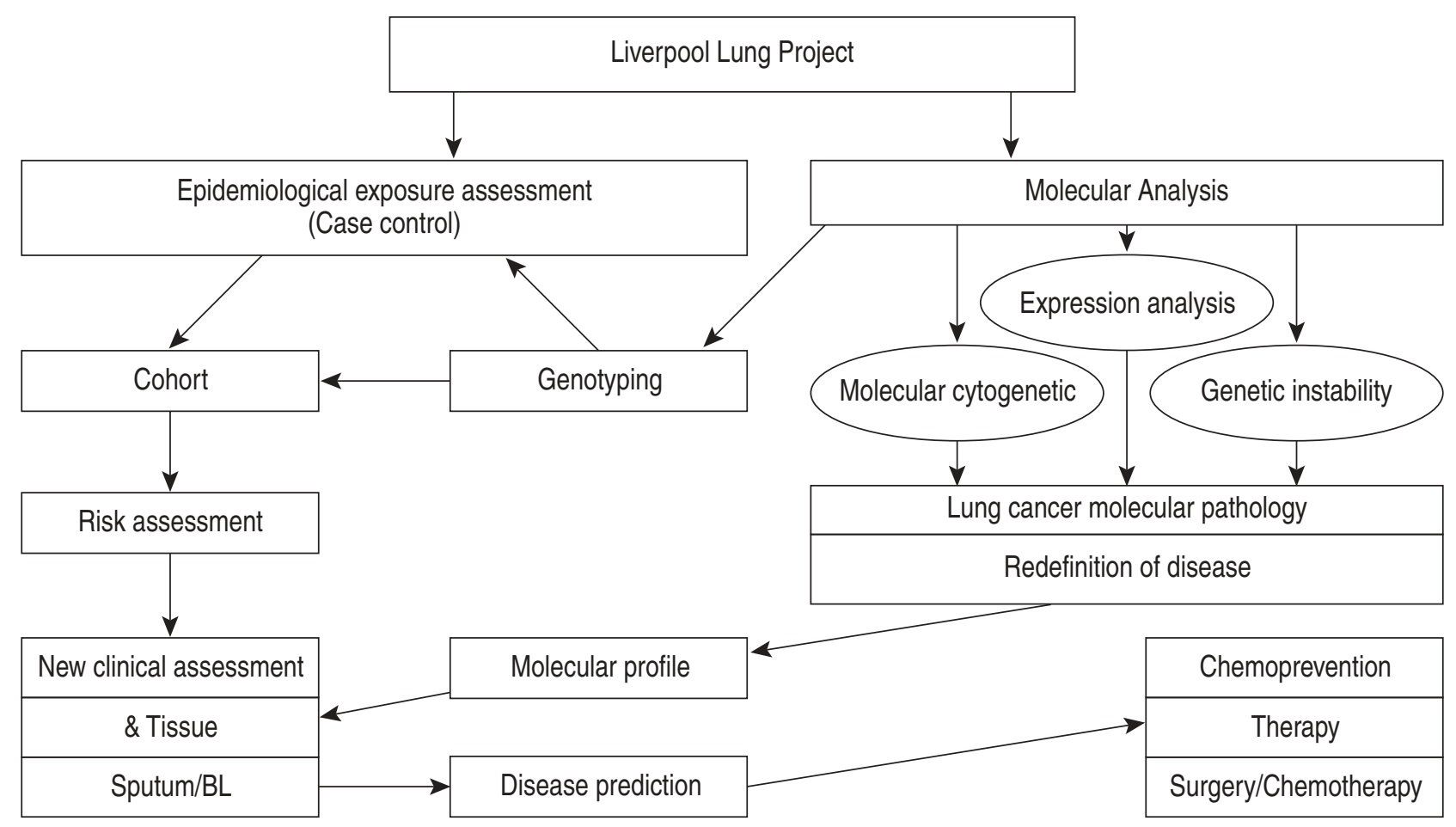

Fig. 2. - The flow diagram of the Liverpool Lung Project. BL: bronchial lavage. 
requires clerical support and fully staffed clinic facilities, which includes a receptionist, research nurse and two medical interviewers. Furthermore, laboratory resources are required to process the specimens and undertake the cytology screening, which includes a technician to log and bar-code all samples, cytology screeners and a technician to prepare DNA from the blood and sputum specimens. In addition a full time research nurse is also required to liaise with clinical staff throughout the six hospital trusts involved with the project and to recruit new lung cancer cases. The LLP currently has two research clinics, The "Tockman Clinic" on the Cardiothoracic Centre National Health Service (NHS) Trust site, which was opened in June 1998 and the Mobile Unit which was launched in July 1999.

\section{The research clinics}

The organisation of the project is based around dedicated, nurse-led community clinics. One of these clinics is a mobile unit. Many of the study population live in socially and materially deprived areas and mobile clinics enable access, raise the profile of the project and give ownership of the project to local communities.

One research clinic can handle $~ 50$ appointments a week giving a maximum annual capacity of $\sim 2,400$. The initial interview may take $\leqslant 2 \mathrm{hrs}$, if a subject has a complicated occupational history, whereas a follow up appointment is usually half this time.

Basic health advice is given, where appropriate, and subjects are provided with a referral letter for their GP if the nurse is concerned for a person's health. Most referrals relate to undiagnosed hypertension (systolic $>160 \mathrm{mmHg}$, diastolic $>105 \mathrm{mmHg}$ ).

Sputum induction. This appears to be a safe procedure for patients with asthma and chronic obstructive pulmonary disease $[155,156]$, although there is no evidence for its use in a population sample. Although the technique produces small changes in spirometry and arterial oxygen saturation these changes are generally asymptomatic and supplemental oxygen is not required. Oxygen levels are monitored throughout the procedure with a transcutaneous handheld pulse oximeter (NPB-40; Nellcor Puritan Bennett UK Ltd, Bicester, UK). Baseline spirometry is performed including forced expiratory volume in one second (FEV1). Post induction FEV1 is also measured to monitor drop in pulmonary function caused by sputum induction. The procedure is generally considered safe at levels of FEV1 of 0.71 or $>50 \%$ of predicted value. A drop in FEV1 is generally detected after 7-10 mins and sputum induction may be discontinued if there is a drop in FEV1 of $>20 \%$. If the patient continues to complain of shortness of breath, bronchodilation with $2.5 \mathrm{mg}$ salbutamol via nebuliser is considered. Any patient with a history of reversible airways disease should receive salbutamol $2.5 \mathrm{mg}$ via nebuliser for pre-induction bronchodilation.

Subjects are advised not to undertake active exercise immediately after sputum induction because of the risk of asymptomatic persistent desaturation.

A portion of the sputum sample obtained is retained for routine cytology screening. Copy cytology reports are sent to the subject's GP. There is little evidence in the current literature for the mechanism of the progression of clones of dysplastic cells. A protocol has been agreed for the management of subjects with mild, moderate or severe atypia. All such subjects are recalled for sputum induction on a 6-monthly basis. Subjects with persistent mild atypia, or moderate or severe atypia are referred to one of two specialist respiratory physicians for further investigation. The follow-up protocol includes annual CT scan and bronchoscopy, together with sputum induction carried out in the research clinic.

\section{Information technology security}

The computer system is protected by a level three firewall and secure sign on technology. Parts of the database are further protected so that only specific members of staff have access to patient identifiers. This level of security complies with the NHS code of connection.

\section{Management of research specimens}

The members of the laboratory staff in the Roy Castle International Centre for Lung Cancer Research support the research clinics by preparing the solutions that are used for sputum induction. They also produce all sample and accompanying data-sheet bar codes to ensure efficient specimen recognition and tracking. Once collected by the research clinics the blood and sputum samples are transported back to the centre, bar coded and logged into the centre's secure database.

Sputum. Before the sputum can be examined cytologically, the lung epithelial cells within the sample need to be fixed onto a glass slide. Firstly, the samples are treated with di-thiothreitol to remove the sticky mucus and then the epithelial cells are centrifuged onto a slide using a cytospin. Four slides are produced, two of which are stained with $\mathrm{H} \& \mathrm{E}$ and two with Papanicolaou. These slides are then screened for the presence of any abnormal cells by Medical Laboratory Scientific Officers under the supervision of a Consultant Cytologist who is based at the Royal Liverpool University Hospital. If the results of this screening procedure are unclear repeat samples may be requested, and, if there are cellular abnormalities present the individuals will be referred to one of the collaborating chest physicians, as per a specific protocol, for further investigation. Such subjects will remain on joint follow-up.

All cytology slides produced are stored in a specially designed room where they will be archived until the end of the project. Remaining specimen material is also stored for future use, with subject consent. The development of any new technique to 
identify malignant or premalignant cells will, of necessity, be compared to the current cytological method of disease identification. Cytology reports are entered into the database and future sputum sample movement is then tracked via the database.

When a batch of 96 different samples has been collected, DNA is extracted from a small amount of each sputum using the Qiagen DNeasy 96 well kit (Qiagen, Crawley, UK). This DNA is checked for quality by PCR, aliquoted, bar-coded and stored at $-85^{\circ} \mathrm{C}$. Storage position of both the sputum and the resultant DNA samples are entered into the database; this capability greatly facilitates use of these samples in the research programme. The DNA prepared from these samples, is at present primarily used by the Genetic Instability Research Group.

Blood. The blood samples are separated by centrifugation into plasma, white cells and red cells; the red cells are discarded. The plasma and white cells are each divided into three portions and are stored at $-85^{\circ} \mathrm{C}$ until required, these samples will be stored for the duration of the LLP.

As with the samples described above the storage position of the whole blood and the resultant DNA are recorded on the LLP database.

Bronchial lavage and tumour specimens. Following consent, one member of staff is based at one of the collaborating hospitals, to obtain samples of tumour tissue, blood and bronchial lavage. In all cases great care is taken not to compromise the diagnostic/ therapeutic process. Solid tissue is either snap frozen in liquid nitrogen or fixed in formalin and embedded in wax, then sectioned for routine $\mathrm{H}$ \& $\mathrm{E}$ staining. Bronchial lavage is mixed with Saccomannos fixative, and routine cytology examination is carried out. All slides prepared from these samples are bar-coded and will be stored until the end of the project. BL samples are coded and stored in a specially designed storage room. The blood sample and all solid tissues are also coded and stored, the blood sample and frozen tissue at $-85^{\circ} \mathrm{C}$, embedded material at room temperature.

Wax-embedded material can be used in the research projects, either as cut sections, in microarray, or as a source of DNA. Microarray technology allows efficient use of valuable material as very small specific samples can be taken and embedded in a fresh wax block, thus, producing a "mini archive" of solid material in each wax block. Results obtained from use of the above samples indicating mutation, $\mathrm{LOH}$ or chromosomal alterations and will be entered into the database alongside epidemiological information.

Freezer security. Plasma, white blood cells, whole blood, DNA extracted from the white blood cell and plasma are bar coded and kept at $-85^{\circ} \mathrm{C}$. The tumour blocks and their associated DNA and RNA are bar coded if within the LLP and stored at $-85^{\circ} \mathrm{C}$. Bronchial lavage and sputum DNA specimens are also bar coded and stored at $-85^{\circ} \mathrm{C}$. The freezer room was purpose built with air conditioning and open vents to maintain the room temp $\leqslant 21^{\circ} \mathrm{C}$. The freezers are connected to uninterrupted power supply and generator back-up in the event of a power failure. The generator is tested monthly. The freezers are also connected to liquid carbon dioxide back up in the event of freezer failure. Each freezer is also connected via its remote alarm connection to the building managed system computer which will send an alarm signal to the laboratory managers office and a staff call out list

The present authors believe this to be the first European early lung cancer detection study, based on nurse-led community clinics, allowing active followup and producing updated lifestyle information and a specimen archive. Over 3,000 individuals have currently been recruited into this project.

Acknowledgements. The authors wish to thank all of their scientific and clinical colleagues who have contributed much to the development and success of the Liverpool Lung Project.

\section{References}

1. Parkin DM. The global burden of cancer. Semin Cancer Biology 1998; 8: 219-235.

2. Wingo PA, Ries LA, Giovino GA, et al. Annual report to the nation on the status of cancer, 19731996, with a special section on lung cancer and tobacco smoking. J Natl Cancer Inst 1999; 91: 765690.

3. Williams EMI. Cancer incidence in Merseyside and Cheshire 1990-1995. Liverpool, The Merseyside and Cheshire Cancer Registry, 1998.

4. Government Statistical Service - Health Statistics Quarterly. Cancer Incidence in England and Wales 1993-1996. London, The Stationery Office, 1999.

5. Coleman MP, Babb P, Damiecki, et al. Cancer survival trends in England and Wales, 1971-1995: Deprivation and NHS Region. London, The Stationery Office, 1999; pp. 281-294.

6. Williams MD, Sandler AB. The epidemiology of lung cancer. Cancer Treat Res 2001; 105: 31-52.

7. Shields PG. Epidemiology of tobacco carcinogenesis. Curr Oncol Rep 2000; 2: 257-262.

8. Steenland K, Loomis D, Shy C, Simonsen N. Review of occupational lung carcinogenesis. Am J Ind Med 2001; 5: 474 490.

9. Boffetta P, Kogevinas M. Epidemiological research and prevention of occupational cancer in Europe. Environ Health Perspect 1999; 107S: 229-231.

10. Evidence and controversies concerning the association between diet and cancer. EPIC (European Prospective Investigation into Cancer) Group in Spain. Med Clin (Barc) 1999; 6: 224-230.

11. Office of National Statistics. In: Health Inequalities. Drever F, Whitehead M, eds. London, The Stationery Office, 1997.

12. Palli D, Russo A, Masala G, et al. DNA adduct levels and DNA repair polymorphisms in traffic-exposed workers and a general population sample. Int $J$ Cancer 2001; 94: 121-127.

13. Cheng L, Spitz MR, Hong WK, Wei Q. Reduced expression levels of nucleotide excision repair genes in lung cancer: a case control analysis. Carcinogenesis 2001; 8: 1527-1530. 
14. Kyrtopoulos SA, Georgiadis $\mathrm{P}$, Autrup $\mathrm{H}$, et al. Biomarkers of genotoxicity of urban air pollution. Overview and descriptive data from a molecular epidemiological study on populations exposed to moderate-to-low levels of polycylic aromatic hydrocarbons: the AULIS project. Mutat Res 2001; 496: 207-228.

15. Lippman SM, Spitz MR. Lung Cancer chemoprevention: an integrated approach. J Clin Oncol 2001; 15: Suppl. 18, 74S-82S.

16. International Agency for Research on Cancer. IARC Monographs on the Evaluations of Carcinogenic Risks of Chemicals in Humans. Vol. 38 Tobacco Smoking. Lyon, International Agency for Research on Cancer, 1986.

17. Peto R, Lopez AD, Boreham J, Thun M, Heath C. Mortality from tobacco in developed countries: indirect estimation from national vital statistics. Lancet 1992; 39: 1268-1278.

18. Brownson RC, Alavanja MCR, Caporaso N, Simoes EJ, Chang JC. Epidemiology and prevention of lung cancer in non-smokers. Epidemiol Rev 1998; 20: 218-236.

19. Wienke JK, Thurston SW, Kelsey KT. J Natl Cancer Inst 1999; 91: 614-619.

20. Department of Health. Statistics on smoking: England, 1978 onwards. Department of Health Statistical Bulletin, Crown Copyright, 2000.

21. Hackshaw AK, Law MR, Wald NJ. The accumulated evidence on lung cancer and environmental tobacco smoke. BMJ 1997; 315: 980-988.

22. Steenland K, Loomis D, Shy C, Simonsen N. Review of occupational lung carcinogens. Am J Ind Med 1996; 29: 474-490.

23. Bofetta P, Kogevinas M. Introduction: Epidemiologic research and prevention of occupational cancer in Europe. Environ Health Perspect 1999; 107: Suppl. 2, 229-231.

24. International Agency for Research on Cancer, World Health Organisation. Chemicals and industrial processes associated with cancer in humans. IARC Monographs vol. 1-20. Report of an ad hoc working group. Lyon, International Agency for Research on Cancer, 1979

25. International Agency for Research on Cancer, World Health Organisation. Monographs on the evaluation of carcinogenic risks to humans. Overall evaluations of carcinogenicity: An updating of IARC Monographs 1-42. Suppl. 7. Lyon, International Agency for Research on Cancer, 1987.

26. Vineis P, Simonato L. Proportion of lung and bladder cancers in males resulting from occupation: A systematic approach. Arch Environ Hlth 1991; 46: 6-15.

27. British Lung Foundation. Transport and air pollution - The health costs. London, British Lung Foundation, 1998.

28. Tomatis L. Cancer: causes, occurrence and control. IARC Sci. Pub. No. 100. Lyon, International Agency for Research on Cancer, 1990; pp. 229-233.

29. Katsouyanni K, Pershagen G. Ambient air pollution and cancer. Cancer Causes Control 1997; 8: 284-291.

30. Morabia A, Wynder EL. Dietary habits of smokers, people who never smoked and ex-smokers. Am J Clin Nutr 1990; 52: 933-937.

31. Margetts BM, Jackson AA. Interaction between people's diet and their smoking habits: the dietary and nutritional survey of British adults. BMJ 1993; 307: 1381-1384.

32. McPhillips JB, Eaton CB, Gans KM, et al. Dietary differences in smokers and non-smokers from two Southeastern New England communities. J Am Diet Assoc 1994; 94: 287-292.

33. Knekt P, Jarvinen R, Seppanen R, et al. Dietary antioxidants and the risk of lung cancer. Am J Epidemiol 1991; 134: 471-479.

34. Alavanja MC, Brown CC, Swanson C, Brownson RC. Saturated fat intake and lung cancer risk among nonsmoking women in Missouri. J Natl Cancer Inst 1993; 85: 1906-1916.

35. Shekelle RB, Rossof AH, Stamler J. Dietary cholesterol and incidence of lung cancer: the Western Electric Study. Am J Epidemiol 1991; 134: 480-484.

36. Hinds MW, Kolonel LN, Hankin JH, Lee J. Dietary cholesterol and lung cancer risk in a multiethnic population in Hawaii. Int $J$ Cancer 1983; 32: 727-732.

37. Goodman MT, Kolonel LN, Yoshizawa CN, Hankin $\mathrm{JH}$. The effect of dietary cholesterol and fat on the risk of lung cancer in Hawaii. Am J Epidemiol 1988; 128: 1241-1255.

38. Jain M, Burch JD, Howe GR, Risch HA, Miller AB. Dietary factors and the risk of lung cancer: results from a case-control study, Toronto 1981-85. Int J Cancer 1990; 45: 287-293.

39. Knekt P, Seppanen R, Jarvinen R, et al. Dietary cholesterol, fatty acids and the risk of lung cancer among men. Nutr Cancer 1991; 16: 267-275.

40. Wu Y, Zheng W, Seller TA, et al. Dietary cholesterol, fat and lung cancer incidence among older women: the Iowa Women's Health Study (United States). Cancer Causes Control 1994; 5: 395-400.

41. Heilbrunn LK, Nomura AM, Stemmermann GN. Dietary cholesterol and lung cancer risk among Japanese men in Hawaii. Am J Clin Nutr 1984; 39: 375-379.

42. Wynder EL, Herbert JR, Kabat GC. Association of dietary fat and lung cancer. J Nat Cancer Ins 1987; 79: 631-637.

43. Potter JD, Sellers TA, Folsom AR, McGovern PG. Alcohol, beer and lung cancer in postmenopausal women: the Iowa Women's Health Study. Annal Epidemiol 1992; 2: 587-595.

44. Kvåle G, Bjelke E, Gart JJ. Dietary habits and lung cancer risk. Int J Cancer 1983; 31: 397-405.

45. Pollack ES, Nomura AMY, Heilbrun LK, Stemmerman GN, Green SB. Prospective study of alcohol consumption and cancer. $N$ Engl J Med 1984; 310: 617-621.

46. Kono S, Ikeda M, Tokudome S, Nishizumi M, Kuratsune M. Alcohol and mortality: a cohort study of male Japanese physicians. Int J Epidemiol 1986; 15: 527-532.

47. Klatsky AI, Friedman GD, Siegelaub AB. Alcohol and mortality: a ten year Kaiser-Permanente experience. Ann Intern Med 1981; 95: 139-145.

48. Bandera EV, Freudenheim JL, Graham S, et al. Alcohol consumption and lung cancer in white males. Cancer Causes Control 1992; 361-369.

49. Steinmetz KA, Potter JD, Folsom AR. Vegetables, fruit and lung cancer in the Iowa Women's Health Study. Cancer Res 1993; 53: 536-543.

50. Dorgan JF, Ziegler RG, Schoenberg JB, et al. Race and sex differences in associations of vegetables, fruits 
and carotenoids with lung cancer risk in New Jersey (USA). Cancer Causes Control 1993; 4: 273-281.

51. Ziegler RG, Subar AF, Craft NE, Ursin G, Patterson GH, Graubard BI. Does beta-carotene explain why reduced cancer risk is associated with vegetable and fruit intake? Cancer Res 1992; 52: 2060s-2066s.

52. Voorips LE, Goldbohm RA, Verhoeven DTH, et al. Vegetable and fruit consumption and lung cancer risk in the Netherlands Cohort Study on diet and cancer. Cancer Causes Control 2000; 11: 101-115.

53. Block G. Vitamin $\mathrm{C}$ and cancer prevention: the epidemiologic evidence. Am J Clin Nutr 1991; 53: 270s-280s.

54. Block G, Patterson B, Subar A. Fruit, vegetables and cancer prevention: a review of the epidemiological evidence. Nut Cancer 1992; 18: 1-20.

55. Kromhout D. Essential micronutrients in relation to carcinogenesis. Am J Clin Nutr 1997; 45: 1361-1367.

56. Shibata A, Paganini Hill A, Ross RK, Yu MC, Henderson BE. Dietary [beta-] carotene, cigarettesmoking and lung cancer in men. Cancer Causes Control 1990; 3: 207-214.

57. Fontham ET, Pickle LW, Haenszel W, Correa P, Lin Y, Flak R. Dietary vitamin A and C and lung cancer risk in Louisana. Cancer 1988; 62: 2267-2273.

58. Le Marchand L, Yoshizawa CN, Kolonel LN, Hankin $\mathrm{JH}$, Goodman MT. Vegetable consumption and lung cancer risk: a population-based-case-control study in Hawaii. J Natl Cancer Inst 1989; 81: 1158-1164.

59. Van den Brandt PA, Goldbohm RA, van Veer P, et al. A prospective cohort study on selenium status and the risk of lung cancer. Cancer Res 1990; 53: 4860-4865.

60. Knekt P, Aromaa A, Maatela J, et al. Serum selenium and subsequent risk of cancer among Finnish men and women. J Natl Cancer Inst 1990; 82: 864-868.

61. Hunter DJ, Morris JS, Stampfer MJ, Colditz GA, Speizer FE, Willett WC. A prospective study of selenium status and breast cancer risk. JAMA 1990; 264: 1128-1131.

62. Hunter DJ, Morris JS, Chute CG, et al. Predictors of selenium concentration in human toenails. $\mathrm{Am}$ $J$ Epidemiol 1990; 132: 114-122.

63. Koo LC. Diet and lung cancer 20+ years later: more questions then answers? Int J Cancer: 1997: Suppl. 10, 22-29.

64. Tomatis L, Kogevinas M, Pearce N, Susser M, Boffetta P. Poverty and lung cancer in social inequalities and cancer. IARC Scientific Publications No. 138. Lyon, International Agency for Research on Cancer, 1997.

65. Williams EMI, Youngson JH, Ashby D, Donnelly RJ. eds. In: Lung cancer bulletin - A framework for action. Liverpool, Merseyside and Cheshire Cancer Registry, 1993.

66. Faggiano F, Partanen T, Kogevinas M, Boffetta P. Socioeconomic differences in cancer incidence and mortality. In: Kogevinas M, Pearce N, Susser M, Boffetta P, eds. Social inequalities and cancer. IARC Scientific Publications No. 138. Lyon, International Agency for Research on Cancer, 1997.

67. Pearce N, Bethwaite P. Social class and cancer mortality in New Zealand 1984-7. New Zeal Med J 1997; 110: 200-202.

68. Van Loon AJM, Goldbohm RA, Vanenbrandt PA. Lung Cancer - Is there an association with socioeconomic status in the Netherlands. J Epi Comm Hlth 1995; 49: 65-69.
69. Bain M, McLaren G. Deprivation and health in Scotland: insights from NHS data. Edinburgh, ISD Publications, 1998.

70. Hart CL, Hole DJ, Gillis CR, Smith GD, Watt GC, Hawthorne VM. Social class differences in lung cancer mortality: risk factor explanations using two Scottish cohort studies. Int J Epidemiolol 2001; 30: 268-274.

71. Sellers TA, Baileywilson JE, Potter JD, et al. Evidence for Mendelian inheritance in the pathogenesis of lung cancer. J Natl Cancer Inst 1990; 82: 272-279.

72. Tokuhata GK, Lilienfeld AM. Familial aggregation of lung cancer in humans. J Natl Cancer Inst 1963; 30: 289-232.

73. Sellers TA, Baileywilson JE, Potter JD, et al. Effect of cohort differences in smoking prevalence on models of lung cancer susceptibility. Genet Epidemiol 1992; 9: 261-271.

74. Hietanen E, Husgafvel-Pursiainen K, Vainio $\mathrm{H}$. Interaction between dose and susceptibility to environmental cancer: a short review. Environ Hlth Perspect 1997; 105: Suppl. 4, 749-754.

75. Gonzalez FJ, Gelboin H. Role of Human Cytochrome P450s in Risk Assessment and Susceptibility to Environmentally Based Disease. J Toxic Environ Health 1993; 40: 289-308.

76. McLemore TL, Adelberg S, Liu MC, et al. Expression of CYP1A1 gene in patients with lung-cancer evidence for cigarette smoke-induced gene-expression in normal lung-tissue and for altered gene-regulation in primary pulmonary carcinomas. $J$ Natl Cancer Inst 1990; 82: 1333-1339.

77. Nebert DW, Gonzalez FJ. P450 Genes - structure, evolution, and regulation. Ann Rev Biochem 1987; 56: 945-993.

78. Mooney LA, Bell DA, Santella RM, et al. Contribution of genetic and nutritional factors to DNA damage in heavy smokers. Carcinogenesis 1997; 18: 503-509.

79. Bell DA, Badawi AF, Lang NP, Ilett KP, Kadlubar FF, Hirvonen A. Polymorphism in the $N$ acetyltransferase 1 (NAT1) polyadenylation signal: association of $\mathrm{NAT} 1 * 10$ allele with higher $\mathrm{N}$-acetylation activity in bladder and colon tissue. Cancer Res 1995; 55: 5226-5229.

80. Cascorbi I, Brockmoller J, Mrozikiewicz PM, Bauer S, Loddenkemper R, Roots I. Homozygous rapid arylamine $\mathrm{N}$-acetyltransferase (NAT2) genotype as a susceptibility factor for lung cancer. Cancer Res 1996; 56: 3961-3966.

81. Hayashi S, Watanabe J, Kawajiri K. High susceptibility to lung cancer analyzed in terms of combined genotypes of P450IA1 and Mu-class glutathione $S$-transferase genes. Jpn J Cancer Res 1992; 83: 866870.

82. Braun MM, Caporaso NE, Page WF, Hoover RN. Genetic component of lung cancer: a cohort study of twins. Lancet 1994; 344: 440-443.

83. Seidegård J. Glutathione $S$-transferases and lung cancer risk. In: Martinet Y, Hirsch FR, Martinet $\mathrm{N}$, Vignaud J-M, Mulshine JL, eds. Clinical and biological basis of lung cancer prevention. Basel, Birkhäuser Verlag, 1998; pp. 213-222.

84. D'Errico A, Malats N, Vineis P, Boffetta P. Review of studies of selected polymorphisms and cancer. In: Vineis P, Malats N, Lang M, d'Errico A, eds. Metabolic polymorphisms and susceptibility to cancer. 
IARC Scientific Publications. No. 148. Lyon, International Agency for Research on Cancer, 1999; pp. 323-393.

85. Jones PA. DNA methylation errors and cancer. Cancer Res 1996; 65: 2463-2476.

86. Chan MF, Liang G, Jones PA. Relationship between transcription and DNA methylation. Curr Top Microbiol Immunol 2000; 249: 75-86.

87. Costello JF, Fruhwald MC, Smiraglia DJ, et al. Aberrant $\mathrm{CpG}$-island methylation has non-random and tumour-type-specific patterns. Nat Genet 2000; 24 : 132-138.

88. Huang TH, Perry MR, Laux DE. Methylation profiling of $\mathrm{CpG}$ islands in human breast cancer cells. Hum Mol Genet 1999; 8: 459-470.

89. Esteller M, Hamilton SR, Burger PC, Baylin SB, Herman JG. Inactivation of the DNA repair gene O6-methylguanine-DNA methyltransferase by promoter hypermethylation is a common event in primary human neoplasia. Cancer Res 1999; 59: 793-797.

90. Ahrendt SA, Chow JT, Xu LH, et al. Molecular detection of tumor cells in bronchoalveolar lavage fluid from patients with early stage lung cancer. $J$ Natl Cancer Inst 1999; 91: 332-339.

91. Palmisano WA, Divine KK, Saccomanno G, et al. Predicting lung cancer by detecting aberrant promoter methylation in sputum. Cancer Res 2000; 60: 5954 5958.

92. Kersting M, Friedl C, Kraus A, Behn M, Pankow W, Schuermann M. Differential frequencies of p16(INK4a) promoter hypermethylation, p53 mutation, and K-ras mutation in exfoliative material mark the development of lung cancer in symptomatic chronic smokers. J Clin Oncol 2000; 18: 3221-3229.

93. Woodson K, Mason J, Choi SW, et al. Hypomethylation of p53 in peripheral blood DNA is associated with the development of lung cancer. Cancer Epidemiol Biomarkers Prev 2001; 10: 69-74.

94. Perucho M. Microsatellite instability: the mutator that mutates the other mutator. Nat Med 1996; 2: 630 631.

95. Lengauer C, Kinzler KW, Vogelstein B. Genetic instabilities in human cancers. Nature 1998; 396: 643-649.

96. Tsuchiya E, Nakamura Y, Weng SY, et al. Allelotype of non-small cell lung carcinoma - comparison between loss of heterozygosity in squamous cell carcinoma and adenocarcinoma. Cancer Res 1992; 52: $2478-2481$.

97. Merlo A, Mabry M, Gabrielson E, Vollmer R, Baylin SB, Sidransky D. Frequent microsatellite instability in primary small cell lung cancer. Cancer Res 1994; 54: 2098-2101.

98. Field JK, Neville EM, Stewart MP, et al. Fractional allele loss data indicate distinct genetic populations in the development of non-small-cell lung cancer. $\mathrm{Br}$ J Cancer 1996; 74: 1968-1974.

99. D'Amico D, Carbone DP, Johnson BE, Meltzer SJ, Minna JD. Polymorphic sites within the MCC and APC loci reveal very frequent loss of heterozygosity in human small cell lung cancer. Cancer Res 1992; 52: 1996-1999.

100. Neville EM, Ross H, Swift A, et al. Allelotype of non small cell lung cancer. Int J Oncol 1996; 9: 533-539.

101. Mitsudomi T, Oyama T, Nishida K, et al. Loss of heterozygosity at $3 p$ in non-small cell lung cancer and its prognostic implication. Clin Cancer Res 1996; 2: $1185-1189$
102. Pifarre A, Rosell R, Monzo M, et al. Prognostic value of replication errors on chromosomes $2 p$ and $3 p$ in non-small-cell lung cancer. Br J Cancer 1997; 75: 184 189.

103. Zhou X, Kemp BL, Khuri FR, et al. Prognostic implication of microsatellite alteration profiles in early-stage non-small cell lung cancer. Clin Cancer Res 2000; 6: 559-565.

104. Liloglou T, Maloney P, Xinarianos G, Fear S. Field JK. Sensitivity and limitations of high throughput fluorescent microsatellite analysis for the detection of allelic imbalance: application in lung tumors. Int $J$ Oncol 2000; 16: 5-14.

105. Field JK. Selection and validation of new lung cancer markers for the molecular-pathological assessment of individuals with a high risk of developing lung cancer. In: Brambilla $\mathrm{C}$, Brambilla $\mathrm{E}$, eds. Lung tumours: fundamental biology and clinical management. Basel, Marcel Dekker, 1999; pp. 287-302.

106. Mulshine JL, Henschke CI. Prospects for lung-cancer screening. Lancet 2000; 355: 592-593.

107. Hung J, Kishimoto Y, Sugio K, et al. Allele-specific chromosome $3 p$ deletions occur at an early stage in the pathogenesis of lung carcinoma. JAMA 1995; 273 : 1908.

108. Kishimoto Y, Sugio K, Hung JY, et al. Allele-specific loss in chromosome 9p loci in preneoplastic lesions accompanying non-small-cell lung cancers. $J$ Natl Cancer Inst 1995; 87: 1224-1229.

109. Kohno H, Hiroshima K, Toyozaki T, Fujisawa T, Ohwada H. p53 mutation and allelic loss of chromosome $3 p, 9 p$ of preneoplastic lesions in patients with nonsmall cell lung carcinoma. Cancer 1999; 85: 341347.

110. Mao L, Lee JS, Kurie JM, et al. Clonal genetic alterations in the lungs of current and former smokers. J Natl Cancer Inst 1997; 89: 857-862.

111. Wistuba II, Lam S, Behrens C, et al. Molecular damage in the bronchial epithelium of current and former smokers. J Natl Cancer Inst 1997; 89: 13661373.

112. Mao L, Hruban RH, Boyle JO, Tockman M, Sidransky D. Detection of oncogene mutations in sputum precedes diagnosis of lung cancer. Cancer Res 1994; 54: 1634-1637.

113. Field JK, Liloglou T, Xinarianos G, et al. Genetic alterations in bronchial lavage as a potential marker for individuals with a high risk of developing lung cancer. Cancer Res 1999; 59: 2690-2695.

114. Miozzo M, Sozzi G, Musso K, et al. Microsatellite alterations in bronchial and sputum specimens of lung cancer patients. Cancer Res 1996; 56: 2285-2288.

115. Ahrendt SA, Chow JT, Xu LH, et al. Molecular detection of tumor cells in bronchoalveolar lavage fluid from patients with early stage lung cancer. $J$ Natl Cancer Inst 1999; 91: 332-339.

116. Powell CA, Klares S, O'Connor G, Brody JS. Loss of heterozygosity in epithelial cells obtained by bronchial brushing: clinical utility in lung cancer. Clin Cancer Res 1999; 5: 2025-2034.

117. Siafakas NM, Tzortzaki EG, Sourvinos G, et al. Microsatellite DNA instability in COPD. Chest 1999; 116: 47-51.

118. Spandidos DA, Ergazaki M, Hatzistamou J, et al. Microsatellite instability in patients with chronic obstructive airway disease. Oncol Rep 1996; 3: 489491. 
119. Park WS, Pham T, Wang C, et al. Loss of heterozygosity and microsatellite instability in nonneoplastic mucosa from patients with chronic ulcerative colitis. Int J Mol Med 1998; 2: 221-224.

120. Suzuki H, Harpaz N, Tarmin L, et al. Microsatellite instability in ulcerative colitis-associated colorectal dysplasias and cancers. Cancer Res 1994; 54: 48414844.

121. Brentnall TA, Crispin DA, Bronner MP, et al. Microsatellite instability in nonneoplastic mucosa from patients with chronic ulcerative colitis. Cancer Res 1996; 56: 1237-1240.

122. Vassilakis DA, Sourvinos G, Markatos M, et al. Microsatellite DNA instability and loss of heterozygosity in pulmonary sarcoidosis. Am J Respir Crit Care Med 1999; 160: 1729-1733.

123. Kullmann F, Widmann T, Kirner A, et al. Microsatellite analysis in rheumatoid arthritis synovial fibroblasts. Ann Rheum Dis 2000; 59: 386-389.

124. Kebelmann-Betzing C, Seeger K, Dragon S, et al. Advantages of a new Taq DNA polymerase in multiplex PCR and time-release PCR. Biotechniques 1998; 24: $154-158$.

125. Liloglou $\mathrm{T}$, Maloney $\mathrm{P}$, Xinarianos $\mathrm{G}$, et al. Cancerspecific genomic instability (CSGI) in bronchial lavage: A molecular tool for lung cancer detection. Cancer Res 2001; 15: 1624-1628.

126. Betticher DC, Heighway J, Thatcher N, Haselton PS. Abnormal expression of CCND1 and RB1 in resection margin epithelia of lung cancer patients. $B r J$ Cancer 1997; 75: 1761-1768.

127. Wistuba I, Behrens C, Milchgrub S, et al. Sequential molecular abnormalities are involved in the multistage development of squamous cell carcinoma. Oncogene 1999; 18: 643-650.

128. Fielding P, Turnbull L, Prime W, Walshaw M, Field JK. Heterogeneous nuclear ribonucleoprotein A2/B1 up-regulation in bronchial lavage specimens: A clinical marker of early lung cancer detection. Clin Cancer Res 1999; 5: 4048-4052.

129. Betticher DC, Heighway J, Haselton PS, et al. Prognostic significance of CCND1 (cyclin D1) overexpression in lung cancer. Br J Cancer 1996; 73: 294-300.

130. Betticher DC, White GRM, Liu X, et al. G1 control gene status is frequently altered in resectable nonsmall cell lung cancer. Intern J Cancer 1997; 74: 556 562.

131. Vonlanthen S, Heighway J, Borner MM, et al. Expression of p16 alpha and beta is frequently altered in resectable non-small cell lung cancer and correlates with p53 overexpression. Oncogene 1998; 17: 27792785.

132. Tockman MS, Mulshine JL, Piantadosi S, et al. Prospective detection of preclinical lung cancer: Results from two studies of heterogeneous nuclear ribonucleoprotein A2/B1 overexpression. Clinical Cancer Res 1997; 3: 2237-2246.

133. Alizadeh AA, Eisen MB, Davis RE, et al. Distinct types of diffuse large B-cell lymphoma identified by gene expression profiling. Nature 2000; 403: 503-511.

134. Saccomanno G, Archer VE, Auerbach O, Saunders RP, Brennan LM. Development of carcinoma of the lung as reflected in exfoliated cells. Cancer 1974; 33: 256-270.

135. Fleishhacker M, Beinert T, Possinger K. Molecular genetic characteristics of lung cancer - useful as "real" tumor markers? Lung Cancer 1999; 25: 7-24.
136. Lee JS, Pathak S, Hopwood V, et al. Involvement of chromosome 7 in primary lung tumor and non-malignant normal lung tissue. Cancer Res 1987; 47: 6349-6352.

137. Sozzi G, Miozzo M, Tagliabue E, et al. Cytogenetic abnormalities and overexpression of receptors for growth factors in normal bronchial epithelium and tumor samples of lung cancer patients. Cancer Res 1991; 51: 400-404.

138. Smith AL, Hung J, Walker L, et al. Extensive areas of aneuploidy are present in the respiratory epithelium of lung cancer patients. Br J Cancer 1996; 73: 203209.

139. Crowell RE, Gilliland FD, Temes RT, et al. Detection of trisomy 7 in non-malignant bronchial epithelium from lung cancer patients and individuals at risk for lung cancer. Cancer Epidemiol Biomarkers Prev 1996; 5: 631-637.

140. Neft RE, Murphy MM, Tierney LA, et al. Concurrent fluorescence in situ hybridization and immunocytochemistry for the detection of chromosome aberrations in exfoliated bronchial epithelial cells. Acta Cytol 1997; 41: 1769-1773.

141. Lechner JF, Neft RE, Gilliland FD, et al. Individuals at high risk for lung cancer have airway epithelial cells with chromosome aberrations frequently found in lung tumor cells. In Vivo 1998; 12: 23-26.

142. Testa JR, Liu Z, Feder M, et al. Advances in the analysis of chromosome alterations in human lung carcinomas. Cancer Genet Cytogenet 1997; 95: 20-32.

143. Mertens F, Johansson B, Höglund M, Mitelman F. Chromosomal imbalance maps of malignant solid tumors: A cytogenetic survey of 3185 neoplasms. Cancer Res 1997; 57: 2765-2780.

144. Mitelman F. Catalog of chromosome aberrations in cancer on-line 2001, cgap.nci.nih.gov/Chromosomes/ Mitelman. Date last updated: May 16, 2002; Date last accessed: June 17, 2002.

145. Kallioniemi A, Kallioniemi O-P, Sudar D, et al. Comparative genomic hybridisation for molecular cytogenetic analysis of solid tumours. Science 1992; 258: 818-821.

146. Knuutila S, Björkqvist AM, Autio K, et al. DNA copy number amplifications in human neoplasms: review of comparative genomic hybridization studies. Am J Pathol 1998; 152: 1107-1123.

147. Knuutila S, Björkqvist AM, Autio K, et al. DNA copy number losses in human neoplasms. Am J Pathol 1999; 155: 683-694.

148. Miller AJ. Subset Selection in Regression. London, Chapman \& Hall, 1990.

149. Carroll RJ, Ruppert D, Stefanski LA. Measurement error in non-linear models. London, Chapman \& Hall, 1995.

150. Medical Research Council. Guidelines - Collections of human tissue and biological samples for use in research 2001. www.mrc.ac.uk/. Date last accessed: June 17, 2002.

151. Siemiatycki J, Day NE, Fabry J, Cooper JA. Discovering carcinogens in the occupational environment: A novel epidemiologic approach. J Natl Cancer Inst 1981; 66: 217-225.

152. Gérin M, Siemiatycki J, Kemper H, Bégin D. Obtaining occupational exposure histories in epidemiologic case-control studies. J Occup Med 1995; 27: 420-426. 
153. Siemiatycki J, Wacholder S, Richardson L, Dewar R, Gérin M. Discovering carcinogens in the occupational environment approach. Scand J Work Environ Hlth 1987; 13: 486-492.

154. Fritschi L, Siemiatycki J, Richardson L. Self-assessed versus expert-assessed occupational exposures. Am J Epidemiol 1996; 144: 521-527.
155. Hunter C, Ward R, Woltmann G, Wardlaw A, Pavord I. Success rate and safety of sputum induction using hypertonic saline. Thorax 1997; 52: Suppl. 6, A15 (S59).

156. Bhowmik A, Seemungal T, Paul EA, Devalia JL, Davies RJ, Wedzicha JA. Safety of sputum induction in patients with COPD. Thorax 1997; 52: Suppl. 6, A15 (S58). 